\section{Proplatelet formation of megakaryocytes is triggered by autocrine-synthesized estradiol}

Yuka Nagata, ${ }^{1,2,5}$ Jun Yoshikawa, ${ }^{2}$

Atsushi Hashimoto, ${ }^{1,2}$ Masayuki Yamamoto, ${ }^{3}$ Anita H. Payne, ${ }^{4}$ and Kazuo Todokoro ${ }^{2,5}$

${ }^{1}$ Recognition and Formation, Precursory Research for Embryonic Science and Technology (PRESTO), Japan Science and Technology Corporation (JST), Japan; ${ }^{2}$ Cell Fate Signaling Research Unit, RIKEN (The Institute of Physical and Chemical Research), 2-1 Hirosawa, Wako, Saitama 351-0198, Japan; ${ }^{3}$ Center for Tsukuba Advanced Research Alliance, University of Tsukuba, Tsukuba 305-8577, Japan; ${ }^{4}$ Division of Reproductive Biology, Department of Obstetrics and Gynecology, Stanford University School of Medicine, Stanford, California 94305-5317, USA

A matured megakaryocyte releases thousands of platelets through a drastic morphological change, proplatelet formation (PPF). The megakaryocyte/erythrocyte-specific transcription factor, p45 NF-E2, is essential for initiating PPF, but the factor regulating PPF has not been identified. Here we report that estradiol synthesized in megakaryocytes triggers PPF. We demonstrate that a key

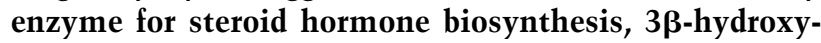
steroid dehydrogenase (3ß-HSD), is a target of p45 NF-E2, and rescues PPF of p45 NF-E2-deficient megakaryocytes. We also show that estradiol is synthesized within megakaryocytes, and that extracellular estradiol stimulates PPF, inhibition of $3 \beta$-HSD activity blocks PPF, and estrogen receptor antagonists inhibit platelet production in vivo. We conclude that autocrine estradiol action regulates platelet production by triggering PPF.

Received July 1, 2003; revised version accepted October 10, 2003.

Platelets are produced from pluripotent hematopoietic stem cells in bone marrow through a unique differentiation process (Kaushansky 1995). Thrombopoietin (TPO) stimulates the differentiation of stem cells to megakaryocytes by polyploidization and cytoplasmic maturation. At the last stage of megakaryocyte differentiation, matured polyploid (16N-128N) megakaryocytes produce several lengthy beaded cytoplasmic processes, and this drastic morphological change, called proplatelet formation (PPF), results in the release of thousands of platelets at once (Radley and Scurfield 1980; Shivdasani et al. 1995; Nagahisa et al. 1996; Italiano et al. 1999; Lecine et al. 2000; Rojnuckarin and Kaushansky 2001). It has been

[Keywords: Sex steroid hormone; p45 NF-E2; proplatelet; $3 \beta-H S D$; hematopoiesis]

${ }^{5}$ Corresponding authors.

E-MAIL y-nagata@postman.riken.go.jp; FAX 81484624827.

E-MAIL todokoro@postman.riken.go.jp; FAX 81484624827.

Article and publication are at http://www.genesdev.org/cgi/doi/10.1101/ $\operatorname{gad} .1128003$. shown that TPO is not required for PPF (Gurney et al. 1994; Shivdasani and Orkin 1995; Shivdasani et al. 1995, 1997; Nagahisa et al. 1996; Bunting et al. 1997; Rojnuckarin and Kaushansky 2001; Oda et al. 2003), and thus the identity of another, as yet unidentified humoral factor that regulates PPF was sought. The search for this PPF-stimulating factor or shedding factor has been unsuccessful to date; thus, the mechanism of PPF and platelet release remains unresolved.

As described below, several lines of evidence suggested that an unidentified intracellular factor, whose expression is up-regulated by the megakaryocyte/erythrocytespecific transcription factor p45 NF-E2, controls PPF. The identification of this key factor has been sought for a long time. p45 NF-E2 is expressed mainly in megakaryocyte and erythroid lineage. Although p45 NF-E2deficient $\left(p 45^{-/-}\right)$mice displayed only mild red blood cell abnormality (Shivdasani and Orkin 1995), p45 ${ }^{-1-}$ mice produced megakaryocytes with premature cytoplasm from which platelets could not be released, and thus lacked circulating platelets and died of hemorrhage (Shivdasani et al. 1995, 1997). In TPO receptor-deficient $\left(c-\mathrm{Mpl}^{-/-}\right)$mice, the number of platelets as well as megakaryocytes was decreased (Gurney et al. 1994; Alexander et al. 1996). The megakaryocytes and platelets remaining in $\mathrm{c}-\mathrm{MpI}^{-}$- mice, however, were functionally normal, and these mice did not exhibit severe bleeding abnormalities (Bunting et al. 1997). In addition, a delay between TPO injection and peak circulating platelet number has been observed in vivo (Farese et al. 1995). These observations strongly suggested that TPO is not required for PPF, but that the expression of another as yet unidentified factor is up-regulated by p45 NF-E2 in megakaryocytes, and it is this factor that triggers PPF. We therefore attempted the identification of this key factor.

\section{Results and Discussion}

Establishment of $\mathrm{p} 45^{-/-}$and $\mathrm{p} 45^{+/+}$ES cells and defect of PPF in $\mathrm{p} 45^{-/-}$megakaryocytes

To identify the target genes of p45 NF-E2 and to study their roles in PPF, it was essential to establish $p 45^{-/-} \mathrm{ES}$ cells, because most $p 45^{-/-}$mice die soon after birth and the required number of megakaryocytes is not available for experimentation. The genotypes of established $p 45^{-/-}$ ES cells as well as $p 45^{+/+}$ES cells were confirmed by PCR analysis (Fig. 1A). In the presence of TPO, p45 $5^{-/-}$ES cells on OP9 stromal cells differentiated into polyploid megakaryocytes but did not display PPF (Fig. 1B, left panel), whereas the majority of $p 45^{+/+}$ES-derived megakaryocytes $\left(p 45^{+/+}\right.$Meg) did exhibit PPF (Fig. 1B, right panel). These data are consistent with in vivo results using $p 45^{-/-}$mice (Shivdasani et al. 1995).

\section{$3 \beta-H S D$ is expressed only in $\mathrm{p} 45^{+/+}$Meg}

By suppressive subtractive hybridization of $\mathrm{cDNAs}$ from $p 45^{-/-}$ES-derived megakaryocytes $\left(p 45^{-/-} \mathrm{Meg}\right)$ and those from $p 45^{+/+} \mathrm{Meg}$, the cDNA fragments encoding $3 \beta$-hydroxysteroid dehydrogenase ( $3 \beta$-HSD), which is a key regulatory enzyme of all steroid hormone biosynthesis (Abbaszade et al. 1997; Peng et al. 2002), were most 
A

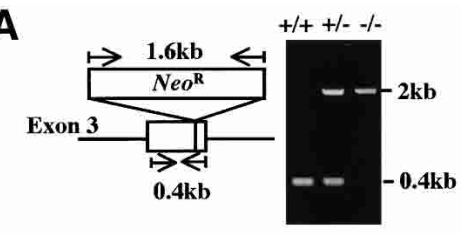

B

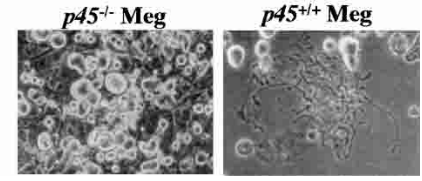

Figure 1. Generation of $p 45^{-/-}$and $p 45^{+/+}$ES cells and PPF assay. (A) Genomic PCR of established $p 45^{-/-}$and $p 45^{+/+}$ES cells. Map of exon 3 region of mouse $p 45$ NF-E2 genomic DNA and the locations of the primers used for PCR (left panel). Agarose gel electrophoresis of PCR products of $p 45^{+/+}, p 45^{+/-}$, and $p 45^{-/-}$ES cells as indicated (right panel). The primers used are $5^{\prime}$-GTTAACTTGCCGGTAGATGACTTT- $3^{\prime}$ and $5^{\prime}$-AGACCAGCTCAATCTGTAGCCTCC-3'. (B) PPF assay of $p 45^{-/-}$Meg and $p 45^{+/+}$Meg. $p 45^{-/-}$and $p 45^{+/+}$ES cells were cocultured on OP9 stromal cells with TPO. (Left) $p 45^{-/-} \mathrm{Meg}$, from which no proplatelet could be formed. (Right) A typical PPF produced from $p 45^{+/+}$Meg.

frequently isolated $(\sim 16 \%$ among the subtracted genes). The cDNAs of both $3 \beta$-HSD I and $3 \beta$-HSD VI were isolated, but the type VI isoform cDNA was the major isoform detected in a ratio of 15 to 1 . To date, only two genes have been identified as targets of p45 NF-E2 in megakaryocytes (Deveaux et al. 1997; Lecine et al. 2000). One of these is a hematopoietic-specific $\beta 1$-tubulin gene (Lecine et al. 2000), which was the second most abundant gene (5\% of the subtracted genes) among the isolated cDNA in our subtraction system. The other is megakaryocyte/platelet differentiation marker, thromboxane synthase gene (Deveaux et al. 1997), which was less abundant among the cDNAs isolated. Several other putative p45 NF-E2 target genes were also isolated. The $3 \beta-H S D$ gene is, therefore, the third gene that was identified as a p45 NF-E2 target.

Northern blot analysis clearly showed that $3 \beta-H S D$ transcripts were abundant in $p 45^{+/+} \mathrm{Meg}$ (Fig. 2A, lane 1), but the transcripts were completely absent in $p 45^{-/-} \mathrm{Meg}$ (Fig. 2A, lane 2). The transcripts of type I and VI isoforms are not distinguishable by Northern blot analysis. The use of RT-PCR followed by specific restriction enzyme digestion (Abbaszade et al. 1997) demonstrated that both type I and VI isoforms were expressed in $p 45^{+/+}$Meg (Fig. 2B, left panel), whereas only the type I isoform was found in bone marrow megakaryocytes (Fig. $2 \mathrm{~B}$, right panel).

To confirm $3 \beta$-HSD expression, we prepared anti-3 $\beta$ HSD I- as well as anti-3 $\beta$-HSD VI-specific antibodies. The immunoblot analysis with these specific antibodies clearly demonstrated that neither type I nor type VI isoform was present in $p 45^{-/-}$Meg (Fig. 2C, lanes 5), but both isoforms were expressed in $p 45^{+/+}$Meg (Fig. 2C, lanes 4). In undifferentiated $p 45^{+f_{+}}$ES cells, however, neither isoform was detected (Fig. 2C, lanes 3), confirming that $3 \beta$-HSD is one of the p45 NF-E2-inducible gene products during megakaryocyte differentiation. Only the type I isoform was expressed in bone marrow megakaryocytes (data not shown). Testis extracts were used as controls (Fig. 2C, lanes 2), because it has been shown that both isoforms are expressed in testes (Baker et al. 1999). These data demonstrated that $3 \beta-H S D$ is ex- pressed only in PPF-producing megakaryocytes. We therefore proceeded to study further the role of $3 \beta-\mathrm{HSD}$ in PPF.

\section{Expression of 3 $\beta$-HSD VI gene rescues PPF} of $\mathrm{p} 45^{-/-} \mathrm{Meg}$

The full-length $3 \beta-H S D$ VI cDNA was transfected into $p 45^{-/-}$ES cells, and the transfectants were cloned by a limiting dilution. Immunoblot analysis confirmed that the cloned transfectants strongly expressed $3 \beta-\mathrm{HSD}$ VI (Fig. 2C, right panel, lane 6). Transfection of $p 45^{-/-}$ES cells with the $3 \beta-H S D$ VI-expressing plasmid rescued PPF of $p 45^{-/-}$Meg (Fig. 3C), whereas the megakaryocytes derived from mock-transfected $p 45^{-/-}$ES cells did not display PPF (Fig. 3A,B). The $p 45^{-/-}$Meg exhibited two types of morphology (Fig. 3A,B), but neither type of megakaryocyte extended the cytoplasmic processes. The majority of $p 45^{-/-}$Meg expressing $3 \beta$-HSD VI did exhibit $\mathrm{PPF}$, indicating that $p 45^{-f-}$ Meg were induced to synthesize a steroid hormone through the expression of $3 \beta$ HSD VI and thus could regulate PPF by an autocrine

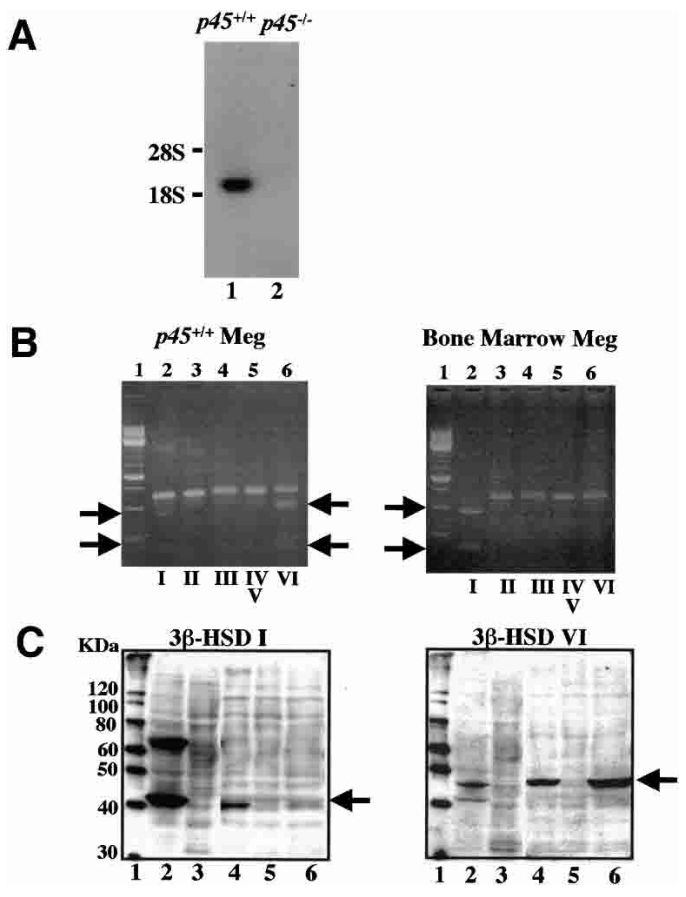

Figure 2. Expression of $3 \beta$-HSD in $p 45^{+/+}$Meg and bone marrow megakaryocytes but not in $p 45^{-/-}$Meg. (A) Expression of $3 \beta-H S D$ transcripts in $p 45^{+/+}$Meg but not $p 45^{-/-}$Meg. Northern blot analysis was performed with $3 \beta-H S D$ cDNA as a probe. (Lane 1) $p 45^{+/+} \mathrm{Meg}$; (lane 2) $p 45^{-/-}$Meg. (B) Expression of $3 \beta$-HSD I and/or VI transcripts in $p 45^{+/+}$Meg and bone marrow megakaryocytes. RT-PCR products of $p 45^{+/+}$Meg (left panel) and bone marrow megakaryocytes (right panel) were digested with unique restriction enzymes, and the isoform types of $3 \beta$-HSD transcripts were determined. Roman numerals below indicate $3 \beta$-HSD isoform types. (Lane 1) Molecular weight marker. Arrows indicate the digested cDNA fragments, showing the presence of the designated isoform cDNA in PCR products. $(C)$ Immunoblot analysis with $3 \beta$-HSD I- and VI-specific antibodies. Total cell extracts prepared from testis (lanes 2), $\mathrm{p}^{4} 5^{+/+}$undifferentiated ES cells (lanes 3), p45 $5^{+/+}$Meg (lanes 4), $p 45^{-/-}$Meg (lanes 5), and $p 45^{-1-}$ Meg expressing $3 \beta$-HSD VI (lanes 6) were probed with anti-3 $\beta$-HSD I-specific antibody (left panel). The same filter was reprobed with anti-3 $\beta$-HSD VI-specific antibody (right panel). (Lane 1) Molecular weight marker. 


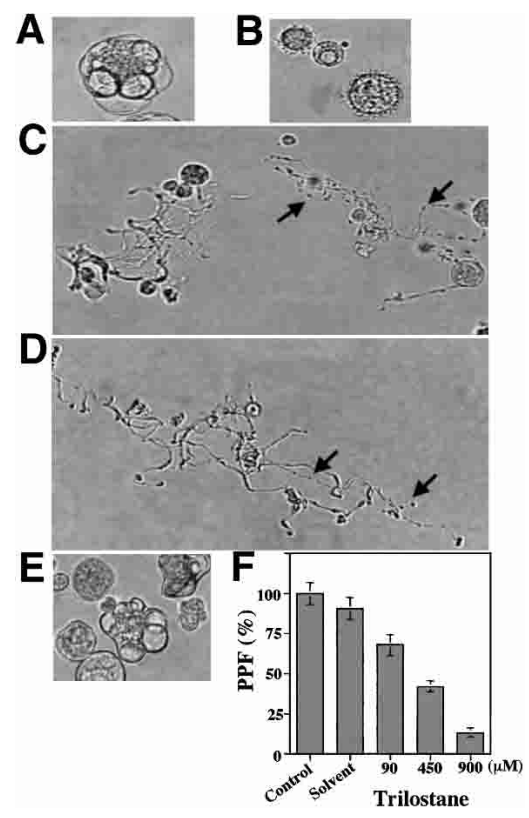

Figure 3. Rescue of PPF ability by forced expression of 3 $\beta$-HSD in $p 45^{-1-}$ Meg and PPF inhibition by trilostane. Cells are shown at the same scale. $p 45^{-1-}$ ES cells were transfected with $3 \beta-H S D$ VI cDNA and/or $\beta 1$-tubulin cDNA in expression vectors. The cloned transfectants were cocultured with OP9 cells with TPO, and megakaryocytes producing PPF were observed. $(A, B)$ Mock-transfected $p 45^{-1-}$ Meg, which cannot display PPF. $(C)$ Two representative proplatelets formed from $3 \beta-\mathrm{HSD}$ VI-expressing $p 45^{-1-} \mathrm{Meg}$. Arrows indicate beaded cytoplasmic processes. (D) A typical PPF of $p 45^{-/-}$Meg expressing both $3 \beta$-HSD VI and $\beta 1$-tubulin. Arrows show long beaded cytoplasmic processes. $(E)$ Trilostane-treated bone marrow megakaryocytes. $(F)$ Dose-dependent inhibition of PPF by $3 \beta$-HSD-specific inhibitor, trilostane. Various concentrations of trilostane dissolved in DMSO were added to bone marrow megakaryocytes, and the number of PPFs formed was counted. Representative data (expressed as mean \pm SEM of triplicate determination) from five independent experiments are shown.

mechanism. These data provide evidence that $3 \beta-H S D$ is essential for PPF in megakaryocytes.

Figure 3C shows two representative proplatelets formed from $3 \beta$-HSD-expressing $p 45^{-/-}$cells. These proplatelets can clearly be characterized as PPF; however, their cytoplasmic processes were not fully extended. Thus, the number of platelets released seemed insufficient, although beaded cytoplasmic processes ready to release platelets were observed (arrows in Fig. 3C). Forced expression of $\beta 1$-tubulin in $p 45^{-1-}$ ES cells was incapable of restoring PPF (data not shown). This is consistent with previous results obtained with $p 45^{-/-}$mouse fetal liver megakaryocytes (Lecine et al. 2000). Therefore, we transfected $3 \beta-H S D$ VI and $\beta 1$-tubulin together into $p 45^{-/-}$ES cells. Figure $3 \mathrm{D}$ shows a typical proplatelet formed from $p 45^{-/-}$Meg expressing both $3 \beta-H S D$ VI and $\beta 1$-tubulin. The proplatelets bearing several lengthy beaded cytoplasmic processes were produced as normal megakaryocytes, indicating that expression of $3 \beta-\mathrm{HSD}$ is indispensable for PPF and that, in addition, $\beta 1$-tubulin is required for completing normal PPF.

\section{3ß-HSD inhibitor trilostane blocks PPF}

The effect of trilostane, a known specific inhibitor of 3 $\beta$-HSD (Potts et al. 1978), on PPF in megakaryocytes isolated from female and male mouse bone marrow was examined. As shown in Figure 3F, trilostane strongly blocked PPF in a dose-dependent manner, whereas the solvent (DMSO) used for dissolving the inhibitor had only a weak inhibitory effect. No gender difference was observed. Trilostane-treated megakaryocytes exhibited irregular shapes, which had several large round intracellular vesicles (Fig. 3E), similar to $p 45^{-/-}$Meg cells (Fig. 3A). They did not extend any cytoplasmic processes and with time underwent apoptosis. The above results also support that activity of $3 \beta-H S D$ in megakaryocytes is a prerequisite for PPF, and that $p 45^{-/-}$Meg as a result of the induction of $3 \beta$-HSD acquire the capacity to synthesize steroid hormones. These observations indicate an autocrine mechanism in megakaryocytes leading to PPF.

\section{Autocrine synthesis of estradiol and expression of estrogen receptor $\beta$ in megakaryocytes}

Immunoblot analysis confirmed that the receptors for androgen, estrogen ( $\beta$ type), and glucocorticoid were expressed in both $p 45^{+/+}$Meg and $p 45^{-/-}$Meg (Fig. 4A), whereas the receptors for estrogen ( $\alpha$ type) and progesterone were not detected (data not shown). The expression of steroid hormone receptors in bone marrow megakaryocytes has been described (Tarantino et al. 1994; Khetawat et al. 2000), although their function was not known.

Furthermore, immunostainings of the cells demonstrated that estradiol and progesterone were actually synthesized in male as well as female mouse bone marrow megakaryocytes (Fig. 4B, lower panels) and in $p 45^{+/+}$ Meg (Fig. 4B, upper panels). Little estradiol and progesterone, however, was detected in $p 45^{-/-}$Meg (Fig. 4B, middle panels). Testosterone was not detected in any megakaryocytes (data not shown), and glucocorticoid synthesis could not be examined because of the unavailability of the antibody. Enzyme immunoassay revealed that male as well as female mouse bone marrow megakaryocytes and $p 45^{+/+} \mathrm{Meg}$, but not $p 45^{-/-}$Meg, secreted $\sim 140 \pm 10 \mathrm{pg}$ of estradiol per $10^{5}$ cells into the medium during $44 \mathrm{~h}$, and that little progesterone and no testosterone were detected in the media.

\section{Extracellular $17 \beta$-estradiol but not testosterone, progesterone, or dexamethasone stimulates PPF}

Because biosynthesis of estradiol and expression of its receptor in PPF-producible megakaryocytes was verified, we examined the effect of $17 \beta$-estradiol on PPF. Addition of $17 \beta$-estradiol to the culture medium of $\mathrm{CD} 41^{+} \mathrm{c}-\mathrm{Kit}^{+}$ megakaryocyte progenitors in the presence of TPO demonstrated a clear stimulatory effect on PPF in a dosedependent manner (Fig. 4C), suggesting that $17 \beta$-estradiol activates specific targets required for PPF or inactivates specific inhibitors for PPF within megakaryocytes. As described above, megakaryocytes can synthesize estradiol, and thus it was unexpected that the addition of extracellular 17 $\beta$-estradiol could stimulate PPF. However, addition of $17 \beta$-estradiol did enhance PPF $>50 \%$, indicating that extracellular hormone could promote further the signals leading to PPF. In contrast, testosterone, progesterone, or the glucocorticoid analog, dexamethasone, had no effect on PPF (data not shown). Progesterone may be synthesized as an intermediate of estrogen, but its receptor is not expressed in megakaryocytes, so that megakaryocytes must be insensitive to progester- 
A

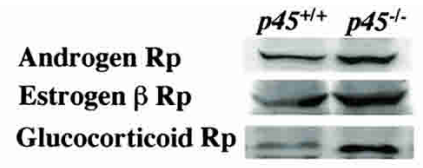

B

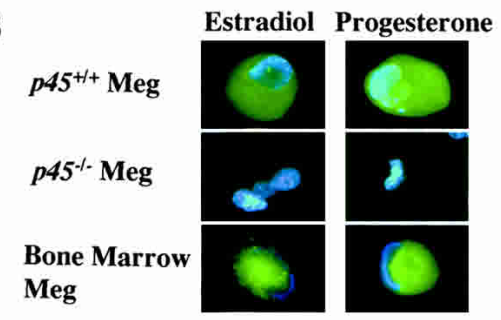

C
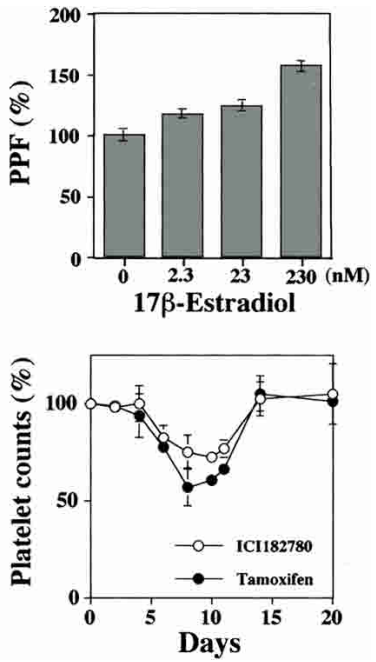

Figure 4. Expression of steroid hormones and their receptors in megakaryocytes, PPF stimulation by $17 \beta$-estradiol, and estrogen receptor antagonists inhibit platelet production. $(A)$ Immunoblot analysis with antisteroid hormone receptor antibodies in megakaryocyte cell extracts. Cell extracts prepared from $p 45^{-/-}$Meg (right lanes) and $p 45^{+/+}$Meg (left lanes) were probed with anti-androgen receptor, anti-estrogen receptor $\beta$, or anti-glucocorticoid receptor antibody, as indicated. (B) Immunostainings of megakaryocytes with anti-steroid hormone antibodies. Bone marrow megakaryocytes (lower panel), $p 45^{-/-}$Meg (middle panel), and $p 45^{+/+}$Meg (upper panel) were stained with anti-estradiol, anti-testosterone, or anti-progesterone antibody (green) and with DAPI (blue). (C) 17 $\beta$-Estradiol stimulates PPF. Various concentrations of $17 \beta$-estradiol were mixed with the culture medium of $\mathrm{CD}^{2} 1^{+} \mathrm{c}$-Kit ${ }^{+}$megakaryocyte progenitors with TPO for $4 \mathrm{~d}$, and PPFs clearly formed were counted. Representative data (expressed as mean \pm SEM of triplicate determination) from five independent experiments are shown. $(D)$ Estrogen receptor antagonists inhibit platelet production in vivo. Mice were treated with tamoxifen (closed circles) or ICI182780 (open circles) for $9 \mathrm{~d}$, and platelet counts were determined as indicated. The platelet counts in the mice treated with solvent alone (sesame oil containing $5 \%$ ethanol) are shown as $100 \%$.

one. Although androgen receptor is expressed, testosterone has no effect on PPF and is not synthesized in megakaryocytes; thus, testosterone is not involved in the process of PPF, as is the case with glucocorticoid, because dexamethasone was found to be without effect.

\section{Estrogen receptor antagonists inhibit platelet production in vivo}

We next examined the effect of estrogen receptor antagonists on platelet production in vivo. ICI182780 or tamoxifen was injected daily for $9 \mathrm{~d}$ into mice, and platelet counts were determined in peripheral blood. The result shows that both antagonists inhibited platelet production in vivo (Fig. 4D). The platelet counts in peripheral blood began to decrease 5-6 d after initial injection, decreased further as long as the antagonist was supplied, and reached the lowest level at 8-11 d (Fig. 4D). The maximal decrease in platelet counts observed with ICI182780 and tamoxifen treatment was 25\% and $45 \%$, respectively. Following termination of the injection, platelet counts returned to the original level within $5 \mathrm{~d}$. As the half-life of mouse platelets is $\sim 5-6 \mathrm{~d}$, the delay of antagonist effect for 5-6 d suggests that the antagonists inhibited the release of newly produced platelets from the megakaryocytes into peripheral blood. These results demonstrate that estrogen receptor antagonists inhibit platelet production in vivo, and confirm that estradiol stimulates PPF and regulates platelet production.

Autocrine-synthesized estradiol triggers PPF of mature megakaryocytes

Taken together, these results support the mechanism that $3 \beta$-HSD expression is upregulated by $\mathrm{p} 45$ NF-E2 during late stages of megakaryocyte differentiation, which, in turn, induces biosynthesis of estrogen in matured megakaryocytes; finally, autocrine estrogen action triggers the last stage of megakaryocyte maturation, PPF, within megakaryocytes. This sex-independent and differentiation stage-specific autocrine steroid action is an effective mechanism for platelet production, because a small quantity of estradiol can efficiently and rapidly bind to its receptor or other targets and act on PPF within the megakaryocytes in the localized microenvironment of bone marrow.

Our results demonstrate that a sex hormone, estradiol, produced in unexpected tissue hematopoietic cells regulates the last stage of its own cell differentiation by an autocrine mechanism. It was reported that progesterone synthesized in the nervous system stimulates myelin formation and neurite growth (Koenig et al. 1995, 2000). Sex steroids may play important roles in cell differentiation of various unexpected tissues in a sex-independent manner as an autocrine rather than paracrine fashion.

Several aspects of the mechanism of PPF have been described. PKC $\alpha$ plays an important role in PPF by altering actin dynamics (Rojnuckarin and Kaushansky 2001), and $\beta 1$-tubulin is involved in PPF (Lecine et al. 2000), as also was observed in our study. These results demonstrate that regulatory components of the cytoskeleton are involved in PPF. Furthermore, overexpression of antiapoptotic protein BclxL or Bcl-2 in megakaryocytes reduced PPF (de Botton et al. 2002; Kaluzhny et al. 2002), and PPF was regulated by compartmentalized caspase 3-directed apoptosis (de Botton et al. 2002; Clarke et al. 2003). These results suggest that platelet production is an apoptotic process. Recently, it was suggested that $N$ methyl-D-aspartate (NMDA) receptor-mediated signaling is involved in megakaryocyte maturation and PPF (Hitchcock et al. 2003). Despite these findings, the upstream key factor triggering PPF has not been identified. We report here that estradiol synthesized in megakaryocytes is the factor regulating PPF. As in the case of a "nongenomic" action described in the central nervous system and cardiovascular system (McEwen et al. 2001; Simoncini and Genazzani 2003), estradiol may modulate NMDA receptor as a membrane receptor, transduce signals leading to PPF, and rapidly and effectively respond to the requirement of platelet production. There is now convincing evidence that paracrine-synthesized estradiol can modulate the functions of neural and vascular cells via nongenomic actions (Kelly and Levin 2001). The rapid response of estradiol as well as the rapid inhibition of $3 \beta$-HSD indicates a nongenomic action, suggesting that this system may function when an emergency requires a quick platelet production. Alternatively, estradiol may also act by binding to the nuclear receptor and up-regulate specific factors activating PPF or down- 
regulate specific inhibitor of PPF as a "genomic" action, as suggested by the detection of estrogen receptor $\beta$ in megakaryocytes. In this case, a lag time is required until the action occurs, and thus this system may effectively function during nonemergency megakaryocyte differentiation. Both nongenomic and genomic actions may work together or cross-talk with each other in platelet production in vivo. Further studies are required for clarifying how autocrine steroid action correlates with the previous observations described above, and which gene products are up-regulated or down-regulated by estrogen receptor $\beta$ in megakaryocytes as a genomic action.

\section{Potential clinical applications of estradiol and

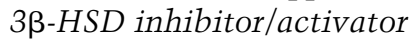

Platelet transfusions are presently the only established therapy for preventing bleeding complications in severely thrombocytopenic individuals such as patients with aplastic anemia or cancer patients on chemotherapy. Furthermore, steroid therapy has been empirically applied for the treatment of various hematopoietic disorders, although its working mechanism was unknown (Negrev 1990; Ranganath et al. 1996; Bord et al. $2000)$. Our findings suggest that $17 \beta$-estradiol or an activator of $3 \beta-H S D$, in combination with a low dose of TPO, is effective for the treatment of thrombocytopenia. Furthermore, there is no useful drug for the treatments of thrombocythemia and thrombocytosis. Our data suggest that inhibitors of $3 \beta$-HSD such as trilostane and estrogen receptor antagonists may be applicable for the treatments of these diseases.

\section{Materials and methods}

$\mathrm{p} 45^{-/}$and $\mathrm{p} 45^{+/+}$ES cells and megakaryocyte differentiation The $p 45^{-/-}$and $p 45^{+/+}$ES cells were established from the blastocysts of $p 45^{+/-}$mice (Jackson Laboratory), and their genotypes were determined by genomic PCR. The pcDNA3.1-3ß-HSD VI was transfected into ES cells by electroporation, and $3 \beta-H S D$ VI expressing transfectants were cloned. The $p 45^{-/-}, p 45^{+/+}$ES cells or transfectants were cocultured with OP9 stromal cells for $3 \mathrm{~d}$ in $\alpha$-MEM containing $20 \%$ fetal calf serum (FCS), and cocultured for a further $8 \mathrm{~d}$ in the presence of recombinant mouse TPO (50 units $/ \mathrm{mL}$ ) with medium changes. Recombinant mouse TPO was prepared as described (Nagata et al. 1995).

\section{Isolation of $3 \beta$-HSD $c D N A$}

Total RNAs were isolated from $p 45^{-/-}$Meg and $p 45^{+/+}$Meg using an RNeasy Mini Kit (QIAGEN). The PCR-Select cDNA subtraction kit (Clontech) was used for cDNA synthesis and suppressive subtractive hybridization, according to the recommended protocol. The cDNA of $p 45^{+/+}$Meg was used as the tester sample, and that of $p 45^{-/-}$Meg as the driver sample. The full-length $3 \beta-H S D$ VI cDNA was isolated and inserted into a pcDNA3.1 expression vector. The $3 \beta-H S D$ VI sequence, in which several nucleotides were different from one in the database, was deposited in the database (accession number AB109387). Northern blot analysis was performed as described (Nagata et al. 2001). The nucleotides $877-1126$ of $3 \beta-H S D$ cDNA was used as a probe.

Determination of isoform type of $3 \beta-H S D$ transcripts

Isoform types of $3 \beta$-HSD transcripts were determined by RT-PCR followed by restriction enzyme digestion procedure as described (Abbaszade et al. 1997). The primers used were 5'-CAGACCATCCTAGATGT-3' and $5^{\prime}$-AGGAAGCTCACAGTTTCCA-3'. The RT-PCR products were digested at the unique restriction site of each isoform-specific sequence and separated by $2 \%$ agarose gel electrophoresis.

Preparation of megakaryocytes and PPF assay

Megakaryocytes from BDF1 mice (6-8-week-old females and males) bone marrow were purified by a modified two-step separation technique as described (Nagahisa et al. 1996). The megakaryocytes $\left(3 \times 10^{3}\right.$ cells $\left./ \mathrm{mL}\right)$ were incubated in serum-free medium (S-clone; Sanko) with $1 \%$ BSA with or without trilostane (Mochida Pharmaceuticals) at $37^{\circ} \mathrm{C}$ for $24 \mathrm{~h}$. The $\mathrm{CD}_{4} 1^{+} \mathrm{c}-\mathrm{Kit}^{+}$cells $\left(2 \times 10^{3}\right.$ cells $\left./ \mathrm{mL}\right)$ prepared as described (Oda et al. 2003) were cultured in S-clone medium with $1 \%$ FCS and mouse TPO $\left(50\right.$ units $/ \mathrm{mL}$ ) with or without steroid hormones at $37^{\circ} \mathrm{C}$ for $4 \mathrm{~d}$. Megakaryocytes displaying clear, long cytoplasmic processes were counted.

Antibody preparation and immunoblot analysis

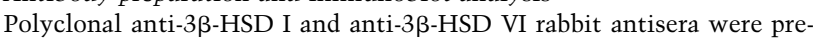
pared by injecting the $\mathrm{N}$-terminal fragment (amino acids 1-267) of $3 \beta$ HSD I and C-terminal peptide (amino acids 360-374) of 3 $\beta$-HSD VI conjugated to KLH, respectively, and $3 \beta-H S D$ VI-specific antibody was purified by antigen affinity chromatography. Immunoblot analysis was performed as described (Nagata et al. 1995). The cell extracts (75 $\mu \mathrm{g})$ and

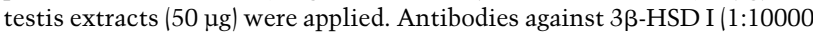
dilution) and $3 \beta$-HSD VI (1:100 dilution), and antibodies against steroid receptors (1:200 dilution; Santa Cruz Biotech) were used. Peroxidaseconjugated AffiniPure $F\left(\mathrm{ab}^{\prime}\right)_{2}$ fragment donkey anti-rabbit IgG (1:20000 dilution; Jackson ImmunoResearch) was used as a secondary antibody.

\section{Immunohistochemical analysis}

Immunofluorescence microscopic analysis was performed as described (Nagata et al. 1997), except for the following points. Smear samples of megakaryocytes were fixed with $3.7 \%$ formaldehyde at room temperature for $15 \mathrm{~min}$. Anti-estradiol antibody (1:20 dilution; Chemicon), antiprogesterone antibody (1:20 dilution; Chemicon), anti-testosterone antibody (Biogenesis), and Alexa Fluor488 goat anti-rabbit IgG $\mathrm{F}\left(\mathrm{ab}^{\prime}\right)_{2}$ fragment (1:600 dilution; Molecular Probes) were used.

Enzyme immunoassay of steroid hormones

An enzyme immunoassay kit (PANTEX) was used to measure quantitatively steroid hormones in the supernatants of megakaryocytes cultured in serum-free medium.

Platelet counts

For platelet counts, $100 \mu \mathrm{L}$ of tamoxifen $(2.5 \mathrm{mg} / \mathrm{mL})$ or ICI182780 $(2.5$ $\mathrm{mg} / \mathrm{mL}$ ) dissolved in solvent (sesame oil:ethanol, 19:1), or solvent alone was injected into BDF1 mice (8-week-old males; $n=7$ ) daily for $9 \mathrm{~d}$, and the number of platelets in peripheral blood were counted.

\section{Acknowledgments}

We thank Hirotaka Haruta for FACS and ES cells, Akira Kato and Etienne-Emile Baulieu for discussion in early stage of this work, Benita Katzenellenbogen for helpful advice, Masaaki Oda for help, and Masahiro Nobuhara for trilostane. This work was supported by PRESTO of JST (Y.N.), by the Bioarchitect project of RIKEN (K.T.), and by NICHD, NIH cooperative agreement as part of the Specialized Cooperative Centers Program in Reproductive Research (A.H.P.).

The publication costs of this article were defrayed in part by payment of page charges. This article must therefore be hereby marked "advertisement" in accordance with 18 USC section 1734 solely to indicate this fact.

\section{References}

Abbaszade, I.G., Arensburg, J., Park, C.H., Kasa-Vubu, J.Z., Orly, J., and Payne, A.H. 1997. Isolation of a new mouse $3 \beta$-hydroxysteroid dehydrogenase isoform, 3 $\beta$-HSD VI, expressed during early pregnancy. Endocrinology 138: 1392-1399.

Alexander, W.S., Roberts, A.W., Nicola, N.A., Li, R., and Metcalf, D. 1996. Deficiencies in progenitor cells of multiple hematopoietic lineages and defective megakaryocytopoiesis in mice lacking the thrombopoietic receptor c-Mpl. Blood 87: 2162-2170.

Baker, P.J., Sha, J.A., McBride, M.W., Peng L., Payne, A.H., and O'Shaughnessy, P.J. 1999. Expression of 3ß-hydroxysteroid dehydrogenase type I and type VI isoforms in the mouse testis during development. Eur. J. Biochem. 260: 911-917.

Bord, S., Vedi, S., Beavan, S.R., Horner, A., and Compston, J.E. 2000. Megakaryocyte population in human bone marrow increases with estrogen treatment: A role in bone remodeling? Bone 27: 397-401. 
Bunting, S., Widmer, R., Lipari, T., Rangell, L., Steinmetz, H., CarverMoore, K., Moore, M.W., Keller, G.A., and de Sauvage, F.J. 1997. Normal platelets and megakaryocytes are produced in vivo in the absence of thrombopoietin. Blood 90: 3423-3429.

Clarke, M.C., Savill, J., Jones, D.B., Noble, B.S., and Brown, S.B. 2003. Compartmentalized megakaryocyte death generates functional platelets committed to caspase-independent death. J. Cell Biol. 160: $577-$ 587.

de Botton, S., Sabri, S., Daugas, E., Zermati, Y., Guidotti, J.E., Hermine, O., Kroemer, G., Vainchenker, W., and Debili, N. 2002. Platelet formation is the consequence of caspase activation within megakaryocytes. Blood 100: 1310-1317.

Deveaux, S., Cohen-Kaminsky, S., Shivdasani, R.A., Andrews, N.C., Filipe, A., Kuzniak, I., Orkin, S.H., Romeo, P.H., and Mignotte, V. 1997. p45 NF-E2 regulates expression of thromboxane synthase in megakaryocytes. EMBO I. 16: 5654-5661.

Farese, A.M., Hunt, P., Boone, T., and MacVittie, T.J. 1995. Recombinant human megakaryocyte growth and development factor stimulates thrombocytopoiesis in normal nonhuman primates. Blood 86: 54-59.

Gurney, A.L., Carver-Moore, K., de Sauvage, F.J., and Moore, M.W. 1994. Thrombocytopenia in c-mpl-deficient mice. Science 265: 1445-1447.

Hitchcock, I.S., Skerry, T.M., Howard, M.R., and Genever, P.G. 2003. NMDA receptor-mediated regulation of human megakaryocytopoiesis. Blood 102: 1254-1259.

Italiano Jr., J.E., Lecine, P., Shivdasani, R.A., and Hartwig, J.H. 1999. Blood platelets are assembled principally at the ends of proplatelet processes produced by differentiated megakaryocytes. J. Cell Biol. 147: 1299-1312.

Kaluzhny, Y., Yu, G., Sun, S., Toselli, P.A., Nieswandt, B., Jackson, C.W., and Ravid, K. 2002. BclxL overexpression in megakaryocytes leads to impaired platelet fragmentation. Blood 100: 1670-1678.

Kaushansky, K. 1995. Thrombopoietin: The primary regulator of platelet production. Blood 86: 419-431.

Kelly, M.J. and Levin, E.R. 2001. Rapid actions of plasma membrane estrogen receptors. Trends Endocrinol. Metab. 12: 152-156.

Khetawat, G., Faraday, N., Nealen, M.L., Vijayan, K.V., Bolton, E., Noga, S.J., and Bray, P.F. 2000. Human megakaryocytes and platelets contain the estrogen receptor $\beta$ and androgen receptor (AR): Testosterone regulates AR expression. Blood 95: 2289-2296.

Koenig, H.L., Schumacher, M., Ferzaz, B., Thi, A.N., Ressouches, A., Guennoun, R., Jung-Testas, I., Robel, P., Akwa, Y., and Baulieu, E.E. 1995. Progesterone synthesis and myelin formation by Schwann cells. Science 268: 1500-1503.

Koenig, H.L., Gong, W.H., and Pelissier, P. 2000. Role of progesterone in peripheral nerve repair. Rev. Reprod. 5: 189-199.

Lecine, P., Italiano Jr., J.E., Kim, S.W., Villeval, J.L., and Shivdasani, R.A. 2000. Hematopoietic-specific $\beta 1$ tubulin participates in a pathway of platelet biogenesis dependent on the transcription factor NF-E2. Blood 96: 1366-1373.

McEwen, B., Akama, K., Alves, S., Brake, W.G., Bulloch, K., Lee, S., Li, C., Yuen, G., and Milner, T.A. 2001. Tracking the estrogen receptor in neurons: Implications for estrogen-induced synapse formation. Proc. Natl. Acad. Sci. 98: 7093-7100.

Nagahisa, H., Nagata, Y., Ohnuki, T., Osada, M., Nagasawa, T., Abe, T., and Todokoro, K. 1996. Bone marrow stromal cells produce thrombopoietin and stimulate megakaryocyte growth and maturation but suppress proplatelet formation. Blood 87: 1309-1316.

Nagata, Y., Nagahisa, H., Aida, Y., Okutomi, K., Nagasawa, T., and Todokoro, K. 1995. Thrombopoietin induces megakaryocyte differentiation in hematopoietic progenitor FDC-P2 cells. J. Biol. Chem. 270: 19673-19675.

Nagata, Y., Muro, Y., and Todokoro, K. 1997. Thrombopoietin-induced polyploidization of bone marrow megakaryocytes is due to a unique regulatory mechanism in late mitosis. J. Cell Biol. 139: 449-457.

Nagata, Y., Oda, M., Nakata, H., Shozaki, Y., Kozasa, T., and Todokoro, K. 2001. A novel regulator of G-protein signaling bearing GAP activity for G $\alpha$ i and G $\alpha \mathrm{q}$ in megakaryocytes. Blood 97: 3051-3060.

Negrev, N. 1990. Female sex hormones and thrombocytopoiesis. Eksp. Med. Morfol. 29: 57-62.

Oda, M., Kurasawa, Y., Todokoro, K., and Nagata, Y. 2003. Thrombopoietin-induced CXC chemokines, NAP-2 and PF-4, suppress polyploidization and proplatelet formation during megakaryocyte maturation. Genes Cells 8: 9-16.
Peng, L., Arensburg, J., Orly, J., and Payne, A.H. 2002. The murine 3 $\beta$ hydroxysteroid dehydrogenase (3ß-HSD) gene family: A postulated role for $3 \beta$-HSD VI during early pregnancy. Mol. Cell. Endocrinol. 187: 213-221.

Potts, G.O., Creange, J.E., Hardoing, H.R., and Schane, H.P. 1978. Trilostane, an orally active inhibitor of steroid biosynthesis. Steroids 32: 257-267.

Radley, J.M. and Scurfield, G. 1980. The mechanism of platelet release. Blood 56: 996-999.

Ranganath, L.R., Christofides, J., and Semple, M.J. 1996. Increased mean platelet volume after oestrogen replacement therapy. Ann. Clin. Biochem. 33: 555-560.

Rojnuckarin, P. and Kaushansky, K. 2001. Actin reorganization and proplatelet formation in murine megakaryocytes: The role of protein kinase C $\alpha$. Blood 97: 154-161.

Shivdasani, R.A. and Orkin, S.H. 1995. Erythropoiesis and globin gene expression in mice lacking the transcription factor NF-E2. Proc. Nat1. Acad. Sci. 92: 8690-8694.

Shivdasani, R.A., Rosenblatt, M.F., Zucker-Franklin, D., Jackson, C.W., Hunt, P., Saris, C.J., and Orkin, S.H. 1995. Transcription factor NF-E2 is required for platelet formation independent of the actions of thrombopoietin/MGDF in megakaryocyte development. Cell 81: 695-704.

Shivdasani, R.A., Fielder, P., Keller, G.A., Orkin, S.H., and de Sauvage, F.J. 1997. Regulation of the serum concentration of thrombopoietin in thrombocytopenic NF-E2 knockout mice. Blood 90: 1821-1827.

Simoncini, T. and Genazzani, A.R. 2003. Non-genomic actions of sex steroid hormones. Eur. J. Endocrinol. 148: 281-292.

Tarantino, M.D., Kunicki, T.J., and Nugent, D.J. 1994. The estrogen receptor is present in human megakaryocytes. Ann. NY Acad. Sci. 714: 293-296. 


\section{Erratum}

Genes \& Development 17: 2864-2869 (2003)

Proplatelet formation of megakaryocytes is triggered by autocrine-synthesized estradiol

Yuka Nagata, Jun Yoshikawa, Atsushi Hashimoto, Masayuki Yamamoto, Anita H. Payne, and Kazuo Todokoro

In the published version of this paper, the vector used for expression of 3 $\beta-H S D$ VI was listed as pcDNA3.1. The $3 \beta-H S D$ VI gene was cloned into a pEGFP-C2 vector, not a pcDNA3.1 vector. The full-length 3 $\beta$-HSD VI protein was expressed in stably transfected cells after proteolytic cleavage at the junction of GFP and 3 $\beta$-HSD VI. Therefore, all the data presented with pEGFP-C2 $3 \beta-H S D$ VI are correct and reproducible, and the conclusions drawn are not affected by this fact.

In the original gel used for the paper (Fig. 2C, right panel, lane 5), a band appeared corresponding to $3 \beta-\mathrm{HSD}$ VI in p45 NFE2 knockout megakaryocytes due to a sample leak from lane 6 and was erased. In previous experiments, we had observed and confirmed that $3 \beta$-HSD VI was not expressed in these control cells by Western blot analyses, and this was also confirmed by Northern blot analysis in Figure 2A. The data presented in the paper is correct and reproducible, and the conclusions are not affected by these errors.

The authors regret these errors, and apologize for any confusion caused by them. 


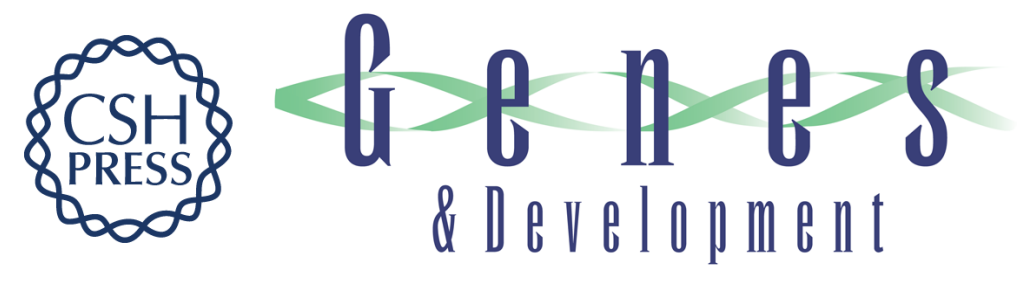

\section{Proplatelet formation of megakaryocytes is triggered by autocrine-synthesized estradiol}

Yuka Nagata, Jun Yoshikawa, Atsushi Hashimoto, et al.

Genes Dev. 2003, 17:

Access the most recent version at doi:10.1101/gad.1128003

\section{Related Content}

References
Errata for vol. 17, p. 2864

Genes Dev. August , 2005 19: 1823

This article cites 34 articles, 25 of which can be accessed free at: http://genesdev.cshlp.org/content/17/23/2864.full.html\#ref-list-1

Articles cited in:

http://genesdev.cshlp.org/content/17/23/2864.full.html\#related-urls

\section{License}

Email Alerting

Receive free email alerts when new articles cite this article - sign up in the box at the top Service right corner of the article or click here.

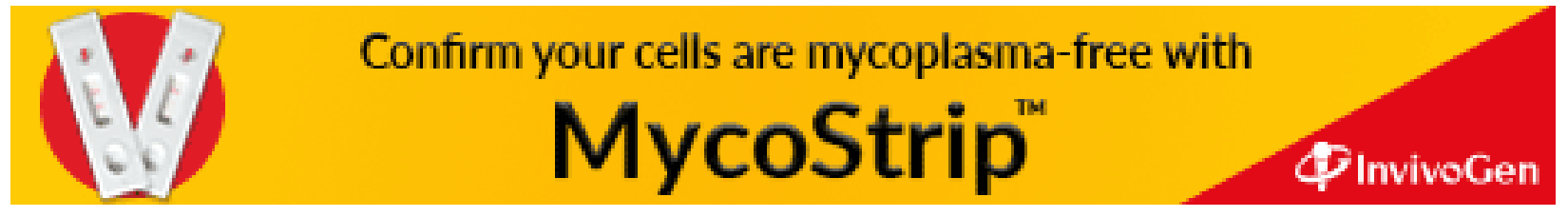

